\title{
The role of children's television programs in developing values for kindergarten child from the teachers' point of view
}

\author{
slue \\ مها الحمد عبد الحليم \\ جامعة المجمعة كلية التربية قسم رياض الأطفال \\ Doi: 10.12816/jacc.2020.123862

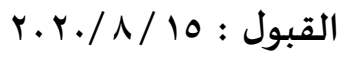 \\ الاستلام: r.r./V/ro

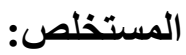

هدفت الدراسة إلى الكثف عن دور البرامج التليفزيونية الخاصة بالأطفال

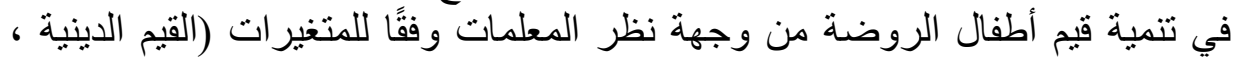

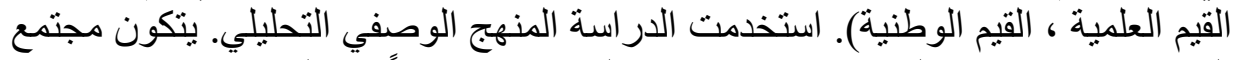

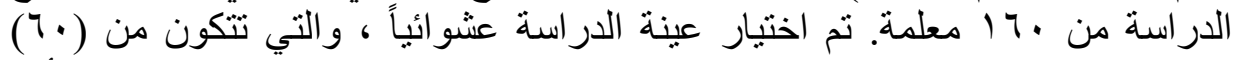

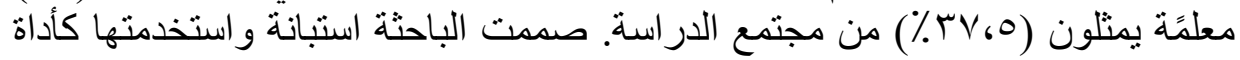
للار اسة. توصلت الدر اسة إلى إلى النتائج التالية:

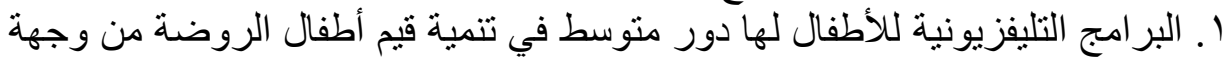

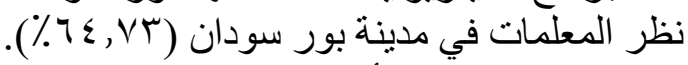

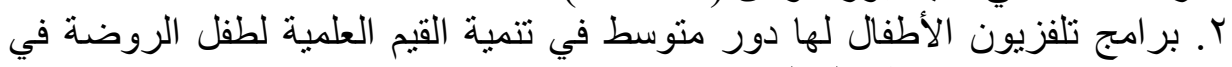

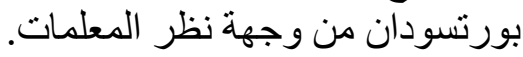
r. هناك دور مهم للبر امج التلفزيونية للأطفال في تتمية القيم الدينية لأطفال الروضة من وجهة نظر المعلمات. ؟. هناك دور صغير لبر لبرامج الأطفال التلفزيونية في تطوير القيم الوطنية لأطفال

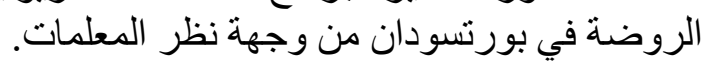

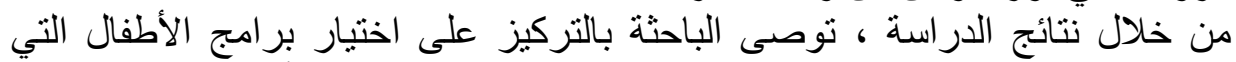

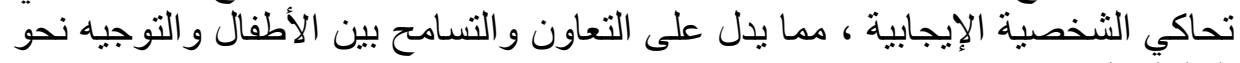
السلورَّ الجيد.

\section{Abstract:}

The study aimed at revealing the role of children's 
television programs in developing values of kindergarten child from the teachers point of view according to the variables (religious values, scientific values, national values). The study used the analytical descriptive method. The study community consisted of 160 teachers.the study sample waschoosed randomly,consisted of(60)teacher, representing (37,5\%) of the study population. The researcher designed a questionnaire and used it as a study tool. The study reached the following results:

1.The children's television programs has a role with a medium degree in the development of kindergarten child 's values from the teachers' point of view in Port Sudan district $(64.73 \%)$.

2. The children's television programshas a role with a medium degree in the development of the scientific values of kindergarten child in Port Sudanfrom the teachers point of view.

3. There is a significant role for children's television programs in the development of the religious values of kindergarten children from theteachers' point of view.

4. There is a small role for children's television programs in developing the national values of kindergarten children in Port Sudan from the teachers' point of view.

Through the results of the study, it is recommended to focus on the selection of children's programs that mimic the positive character, which indicates cooperation and tolerance among children and guidance towards good behavior. Keywords: children's TV programs, values, kindergarten child, religious values, scientific values, national values. 


\section{Introduction:}

The researchers concerned television as the third father of the child, or the child's spiritual father, so television is a media of particular interest to the child if we are looking for a better future, since childhood is the maker of the future. Television is the most popular mass media for children. It attracts children in different stages of childhood. In the age of two years, television draws the attention of the child, begins to track the sound and then focuses on the picture. Over time, his programs become an important part of his time. His interest in television programs has become more and more relevant to him, and he has a desire to choose and prefer one program to another. Watching television is at the top of cultural activities for children, and this is precisely their culture. (Wahida Boufdah Bidi, 2017: 2)

TV programs for children are widely watched by television stations around the world, whether in the East or the West, regardless of their policies, affiliations and political, economic or social conditions. This concern stems from the perception of children and childhood as an important social target. TV and other means of communication must seek educational and guidance functions that will contribute to raising the child's culture, diversifying his knowledge, expanding his awareness, and supporting other cultural and social institutions such as school and the family as part of an effort to create a conscious generation of children who will become good men in the future. (Tasnim Ahmed, 2015: 2)

\section{The study Problem:}

The research problem can be identified in determining the role that TV can play in giving children educational knowledge 
and values through the television programs that it provides to them. In fact, the target age of the study, which is between 612 years, is considered the stage of need for this information. As it is an important corner without which skills, knowledge and values cannot be acquired. It also plays an important role in his life, both in his directions and in his behavior.

\section{Previous studies:}

1-Alyan Abdallah Elhawly(2004): The Effect of Animation on Nectal Values for Children, Palestine:.

The study aimed to identify the effect of animation on the values of nodal children, through the analysis of a number of animation films in a number of channels specialized for children, the first channel in Saudi TV, and a sample of selected videos.

The study found a number of results, the most prominent of which are: The nodal values in the sample of the study have positive aspects of faith in God, faith in angels, books; and negatives contained in the terms contained in the values of the nodal. The study recommended the need to seek to instill the Islamic beliefs contained in the animation films

2-Al-Orabi and Mahmud (2006): The Values in the Animation Series of Saudi TV.

The aim of the study was to know the content of the animation films and the values through which they are presented and their role in raising a child. The researcher used the method of content analysis through a random sample of three animated films dubbed and choosed random loops and analyzed them using a questionnaire that they designed. The study found the following

results: 
1. Negative values outweigh the useful values in the animation provided to children in Saudi TV.

2. The child's interaction with the film may reach the limit of the tradition, which negatively affects the child's personality.

3-Ziad Ben Ali Mahmud (2011): The role of children's TV programs in promoting the values of the Palestinian child from the point of view of some kindergarten workers.

This study aims to reveal the contributions of some Muslim scholars in the education of the child. The researcher used the historical method in his study to answer the questions of the study. He found that there are contributions to Muslim scholars in the social upbringing of the child and there are contractual, social, psychological, education . The study also revealed the existence of educational and social institutions that broadcast the science and knowledge of the Muslim child and raised in their arms on the guidance of Islam. The study recommended a number of recommendations, the most important of which is to work on building an Islamic educational theory, A mercy in childhood and a guarantee of human happiness.

4-Tasnim Ahmed Mukhaimar (2015): Values in children's TV programs "Mbc3 channel programs model.The study aimed to identify the techniques used by the children's television programs in the "mbc3" programs, as well as to identify the values that these programs contain in terms of religious, social, national, political, scientific values and negative behavior values. The research used the descriptive method in the content of analysis method. The study tool was the content analysis form used to collect the study sample data which was (32) programs. 
To provide accurate and clear results, the researcher did a number of procedures including reading a lot of literature related to the study, viewing relevant videos and television interviews, setting up a schedule to monitor the dates of broadcasting the programs that represented the study sample, Programs for audit and evaluation purposes.

One of the most important findings of the study was that the most important values included in the children's TV programs on "mbc3" programs are the values of negative behaviors. Violence in all its forms ranked first in all the sub-values included in children's programs on MBC3. In addition, the lowest values included in these programs are national values and scientific values.

\section{5-Mohammed Jassim Falhi, Saeed Miftah Hamad Saeed} (2015): The Educational Role of Children's Programs in Libyan Television. An Analytical Field Study of the "Flowers of Life" Program.. The aim of the research is to learn about the child-oriented programs on Libyan television through a comprehensive analysis of the "Flower of Life" program during the 2004 broadcast season from April 1, 2004 to June 30,2004 . It also focuses on trying to identify The Libyan TV policy in broadcasting educational content through children's programs in the prevailing political and social conditions through the study period the study also aimed to knowing the views of the study sample (children) in El-Baida city and their views in the children's programs in general and the program ( flowers of life) in particular. so this study aimed to identify the role of the program ( flowers of life) in transmitting the educational, Program on the cognitive and social side in Libya. 
Comments on previous studies: Note that all previous studies did not give direct attention to the subject of religious, scientific, aesthetic and national values. The studies also discussed variables that differs from the current study variables, and were conducted in environments that different from the Sudanese one.

\section{Study Questions:}

The study tries to answer the following questions:

1. What is the role of children's television programs in the development of kindergarten child values from the teachers' point of view?.

2. What is the role of children's television programs in the development of the religious values of kindergarten children from the teachers' point of view? .

3. What is the role of children's television programs in the development of the scientific values of kindergarten children from the teachers' point of view?

4. What is the role of children's television programs in the development of the national values of kindergarten children from the teachers' point of view?

\section{The importance of study:}

The interest and care of what is presented by television is now an urgent necessity for all of us to help young people to develop their personality and their values and refining their talents and maintain good citizenship, and in order to use this means to transfer interest and bring the religion of Islam and show the greatness of the rising generations and highlight some virtues and Islamic ethics such as honesty, Sacrifice, and altruism through wonderful storytelling and meaningful 
novels. Television is capable of teaching children the social behavior that parents value.

The importance of the study is as follows:

1.The scarcity of research related to educational values, especially in the specialized channels. No Arab, regional, or local study was conducted on the content of specialized channels directed at the child.

2. Growing interest in the nature of media contents, especially educational, aimed at young people, not only at the local level but also globally. Educational values in developed countries have become an essential tool for local and international media. Society and its constants in general.

3. To highlight the role and potential of specialized channels in the field of education, especially as a communicative mediator with the ability to instill new values of any kind.

4. This study is expected to produce a set of recommendations for parents and those who work in the field of childhood.

\section{Objectives of the study:}

Based on the above, the problem, questions and importance, the objectives of this study are:

1. Disclosure of the role of children's television programs in the development of kindergarten child's values from teachers' point of view.

2. Identify the role of children's television programs in the development of children's religious values from teachers' point of view.

3. Know the role of children's television programs in developing the child's scientific values from teachers' point of view. 
4. Know the role of children's television programs in the development of children's national values from teachers' point of view.

\section{The limits of the study:}

This study is limited with the topic the role of children's television programs in the development of values (religious, scientific, and national) of kindergarten children from the teachers' point of view, applied in Redsea State, portSudan , Southern Unit, 2018-2019.the study sample was kinder garten teachers.

\section{Terminology of the study:}

Television: The researcher defines the procedure as (one of the mass media provides the viewer with voice, motion and image via the emergence of terrestrial or space broadcasting).

Television programs: The researcher can know them in a procedural way (everything that is intended for directing to children ( songs, animations, plays, movies, games, etc.).

The value: in language it means integrity (Ibn Manzoor, 1981: 406), and educators defined it as: a set of laws and goals and ideals that guide the human relationship with the physical world, social or heavenly (Afifi, 1970: 37)

In this study the researcher adopted Hamid Zahran's definition of values which claimed that value is (a regulation of the provisions of an emotional mentality that is generalized towards people, objects, meanings and aspects of activity, as well as an expression of human motives and the things that direct their desires and tendencies towards them." Or credits that relate to persons, objects, meanings or aspects of activity).( HamidZahran: 2000: 15) 


\section{The theoretical frame of the study: Conceptof Values:}

Values are of the basic concepts that sociologists have taken care of. The term "value" has been widely used to refer to multiple meanings related to the daily life of individuals, such as the price of objects, the social status of people, the usefulness of objects, subjects and ideas. The term value is not used in sociology and anthropology except in the early 20th century, the use of other alternatives such as morality, virtues, ideals, goodness, justice, beauty, and value was originally used as an economic term synonymous with price. It was borrowed from economics to refer to specific concepts in psychology, Anthropology, and its use has expanded to the point of entering politics and history. (Stashev and Rudy Pritz: 20)

The values are: "a way of existence or behavior that is recognized by a person or group as an example, and makes the actions or individuals to whom it is attributed desirable or appreciated (or vice versa in the case of negative values)." , (Andre \& Glicksman,2000: 70)

\section{Building and configuring of values:}

The values are assumed to be the presence of a number of factors as highlighted by Abul-Enein (1988: 84):

1.The conviction of the importance of value: The value and adoption of any value depends on the factor of acceptance, which is the most important factor in the establishment of values in the individual. This is because a person often accepts the value of something without having any direct contact with the objects or related subjects. The direction or composition of a land is not acquired, but is determined by the general social 
norms that children absorb from their parents without criticism or thought, becoming a normal part of their traditions and civilization that they find difficult to dispose of. Inspiration plays an important role in the formation of this type of trend, because it is one of the means by which the prevailing norms in society acquire religious, social, moral or aesthetic. If the tendency in a country is democratic, the individuals adopt this principle.

2.Value preference: This stage means that the individual becomes so committed to the value that he follows value and seeks and wants it. Here are some specific responses that express this preference; in the case of the value we represented, the individual seeks to form a wide ground, or is interested in inviting others to pray, and go to the mosque voluntarily.

3.The power of readiness to accept value: A situation that is associated with value (experience, expert, position ...) is considered valuable, if it is powerful and has a positive impact on one's life, making it highly correlated with the value associated with it. A negative impact on the individual he lives in, he often attests to the values he carries, and a strong, positive attitude helps to create attitudes that strengthen the propensity to value.

¿.Discrimination: At this stage, the individual becomes distinct. He reaches the self-consistent behavior according to the values he represents. He controls and monitors his actions. $\mathrm{He}$ acts as a controller of his behavior, so that these values can be described and appreciated. The learner at this stage has integrated his values, ideas, attitudes and tendencies into an integrated view that shapes his outlook on the world around

1.0 
him and forms his constant and consistent responses to attitudes and things in a coherent way. The meaning is that it constitutes a fundamental behavioral trend that enables the individual to control the complex world around him and to work consistently and effectively in this world, linking this basic orientation with a series of attitudes, and values. Thus, the individual reaches the representation of values and integrates them into himself so that they become characteristic of him, and he accepts the attitudes, trends, laws and principles that form part of him, in the formation of the values Components of values:

Values consist of three main levels:

A. The cognitive component: the criterion of choice, that is, the selection of value from different substitutions in complete freedom so that the individual considers the consequences of selecting each alternative and is responsible for its entire selection, meaning that involuntary reflection is not a choice related to values.

The choice is the first level in the scale leading to the values, and consists of three degrees or consecutive steps are:

Explore the possible substitution, consider the consequences of each alternative, then free choice.

B. The emotional component: The criterion of "appreciation" reflected in the attachment to the value and pride, and the sense of happiness to choose and the desire to publicize.

The estimate is the second level in the scale leading to the values and consists of two steps:

Feeling happy to choose value, and declaring value to the public 
C. Behavioral component: The term "practice and work" or "act" includes the actual practice of value or practice in a manner consistent with the value chosen, provided that practice is repeated continuously in different situations whenever the opportunity arises. Practice is the third level in the scale leading to values, consisting of two sequential steps: translating value into practice, and constructing a value pattern

\section{Sources of Values:}

Values have many sources, and these sources vary from one society to another. In Arab and Islamic societies, the sources of values can be summarized as follows:

The Islamic religion: represented in the book of Allah and the Sunnah of His Messenger peace be upon him and the consensus and diligence, and this source is the main source of values in our society, although taking hold of them gradually weaken until God sends to the top every hundred years of renewing this nation matters of religion, Islam has become strange and will return strange and blessed strangers. All values derived from this source is the whole good, and the source of happiness for mankind in its world and the last if the right to stick to the right.

1.The pre-Islamic period: there are values that many people still adhere to and were prevalent in the pre-Islamic era. Some of these values are positive values such as brotherhood, courage and relief. Some of these values negatively affect people and society, such as tribal fanaticism and avenging.

2.We have received many values from the non-Islamic world. Some of these values are positive and beneficial values such 
as systemic scholarship and planning. There are negative values such as family disintegration and lack of social ties.

3.Methodological study materials: There have been many educational values at the educational level, most of which are useful and useful if applied properly, taking into account our reality and our circumstances. These values include: inference, accuracy, questioning, brainstorming.etc. (Elnashif, 1981: 82).

Values properties: Values - in general -have several characteristics are summarized as follows:

- The values have an abstract meaning, but must be caught in reality and behavior, values must be insured by the human to be directed to his behavior so that it can be considered valuable, and therefore the Holy Quran often said "those who believe and do good deeds" In the Hadith (religion is dealing)

- Knowledge of tribal values does not come suddenly, mental awareness must be available with values, and must be accompanied by emotional emotion.

- Values require selection, and this requires that we have freedom.

- The value hierarchy is not static but moving, and the value peace may vibrate negatively or positively.

-Values are directed at the individual and his behavior in life.

- The values of distinguishing marks "distinctive" that they have indicators through which we differentiate between them and customs.

- The values are interrelated and interdependent, as they include the cognitive, emotional and behavioral aspects as they are included in terms of application. For example, justice is a political value and a moral value as well. 


\section{Values Indicators:}

There are indicators of values, and distinguish between them and habits and these indicators are the emergence of a person's interests in value and trends towards it, in addition to the hopes and aspirations, feelings, beliefs, convictions, activities, actions and concerns and problems through which all of them that this person adopts the value of millions, and through these indicators is clear. The cultural depth of values in addition to the three components of cognitive, emotional and behavioral.

\section{Classifications of values:}

the values were classified in several categories according to a number consideration. -Hafawi, Ghazi (1986: 26) classified values into three areas:

Values of mentality, aesthetic values and ethical values.And classified them on the basis of what is tangible material and intangible.

A. Physical assets b. Spiritual values.

And classified by Tahtawi (1996: 48) according to persons:

a. Values of the theory of economic values. Social values e. Religious Values. Political values g. Technical values.

\section{B. The concept of television programs:}

Sawalha(2003: 3)defined television program as a flowing stream of visuals, audio and video, and television programs of different types of television. There is no television material outside these flowing forms of television material. The television program is an idea that exists and is treated artistically using television as a means available to it the potential of the media. 


\section{The concept of children's television programs:}

It is known as (Edward Stasheff and Rudy Britts (.N Y 66), programs which is specially designed for children such as contests, animations, cartoons, children's gifts, and all the fun and joy.

\section{The television:}

Television is one of the important media in the continuous education of the dissemination, which is one of the modes of open education, which helps the learner to acquire a lot of values, concepts, and trends (friend, 1993: 152).

It has some characteristic:

a. Television is an educational, and recreational tool.

B. The viewer can listen and watch while doing other work.

C. Gives the viewer the freedom to choose more than one channel.

D. Group TV viewing.

E. The viewer can be addressed in language by translating programs into more than one language or broadcasting on more than one channel.

\section{Television and its impact on children's lives:}

The educationalists aspire to have a television as a window that looks at broad horizons that will help children develop psychologically and mentally, and help satisfy their needs and prepare them for school and life. Recognizing that television is a double-edged sword, it can lead to counterfeiting of consciousness, frustrations, disrupts the imagination of the imagination, encourages consumerism through advertising, promotes stereotypes, leads to early child maturation and fosters the spirit of violence. 
On the other hand, if used better, it can be an important factor in socialization; it can inculcate positive values of all kinds, foster a sense of national and national belonging, and can provide children with new information that is difficult to see directly, and can increase his linguistic wealth, and to teach him some good behavior; that is, television can contribute to the formation of the child's personality and the building of his culture.

\section{Child and television:}

For young children, television is especially something that is soon, simple and amazing. At first sight, everything seems clear and agreed, with television playing a very important role in the upbringing of children. The goals set by that device make it a partner for the family, school and society, so we often hear parents complaining: "Sure, television is a great achievement, but ..." and then followed by many of its negative aspects. (Khadour, 2003: 36)

\section{Child's relationship with television:}

It can be said that television is the first mass communication medium with which children begin direct contact without an intermediary, because since birth, man has shown a lot of behavior directed towards the outside world that results in accumulation of information. It has become a cognitive fact that children during the first weeks of their lives prove to any source of light. (Salih, 1981: 11)

The child's relationship with television begins at the age of two, when a random listening to a program is heard by someone else, even if the child reaches the age of three can ask for his favorite program, and of course, this is within the programs of children. 
Through the above, the researcher concludes that the child in the early stage does not distinguish between reality and fiction, which is related to the television screen. The latter enchanted the little viewer and took over all his senses and took control of his thinking. Therefore, parents should choose the animation programs that their children watch, because they have an important role in transferring the child to another world; the world of distant and different fantasies, so as not to be a reason to isolate the child from his family and social environment in general and thus cause harm to his social development. While we find the child in the middle stage distinguish reality from fantasy. Television should therefore provide a transition from fantasy to reality in a gradual manner, and also provide patterns of behavior appropriate to the family environment to which the child belongs

\section{Field study procedures:}

\section{The Study Approach:}

The study depends on the descriptive approach that describes a specific situation or factor on a phenomenon, and then observation and analysis of the results.

\section{The Study population:}

The study population consisted of (160) kinder garten teachers according to the statistics of pre-school education office in southern unit - portSudan locality

\section{The Study Sample:}

The sample of the current study was (60) kinder garten teachers selected in a simple random way and represent $(37,5 \%)$ from the study population.

The following tables illustrate the distribution of the study sample according to its specifications: 
Table (1) Distribution of the study sample according to the variables (scientific qualification, years of experience and specialization)

\begin{tabular}{|c|c|c|c|}
\hline variable & pheasant & frequency & percent \\
\hline \multirow{4}{*}{ Qualification } & secondary & 26 & $43 \%$ \\
\cline { 2 - 4 } & diploma & 13 & $21 \%$ \\
\cline { 2 - 4 } & BA & 21 & $36 \%$ \\
\cline { 2 - 4 } & Total & $\mathbf{6 0}$ & $\mathbf{1 0 0 \%}$ \\
\hline \multirow{4}{*}{ Years of Experience } & $1-5$ years & 16 & $26.7 \%$ \\
\cline { 2 - 4 } & 6-10 years & 18 & $30 \%$ \\
\cline { 2 - 4 } & Over 10 years & 26 & $43.3 \%$ \\
\cline { 2 - 4 } & Total & $\mathbf{6 0}$ & $\mathbf{1 0 0 \%}$ \\
\hline \multirow{4}{*}{ Specialization } & Kindergarten & 10 & $16.7 \%$ \\
\cline { 2 - 4 } & psychology & 8 & $13.3 \%$ \\
\cline { 2 - 4 } & Sociology & 10 & $16.7 \%$ \\
\cline { 2 - 4 } & Others & 32 & $53.3 \%$ \\
\cline { 2 - 4 } & Total & $\mathbf{6 0}$ & $\mathbf{\% 1 0 0}$ \\
\hline
\end{tabular}

Table (2) shows that the number of teachers in the secondary category reached 26 (43\%), diploma (13), 21\%, and (21) . It is also clear that the number of female teachers in the category of years of experience (1-5 years) was 16, 26.7\%, 610 years were 18 years, $30 \%$ (26\%) and by (43\%).

\section{The Study tool:}

The researcher designed a questionnaire to measure the role of children's television programs in developing values for kindergarten children from theteachers point of view in Port Sudan., the questionnaire included three axes (scientific values, religious values, and national values).

The questionnaire consisted of (15) paragraphs of the three axes representing the values requiring response according to the Likert scale, as shown in Table (2): 
Table (2) The five - dimensional Likert scale:

\begin{tabular}{|c|c|c|c|}
\hline Grades & 5 & 3 & 1 \\
\hline Rank & Big & Medium & small \\
\hline
\end{tabular}

The researcher verified the validity of the tool by adopting the method of sincerity of the arbitrators. The questionnaire was presented to a group of arbitrators with experience and competence. The arbitrators presented their valuable opinions, observations and directives which led to the appropriate amendments in terms of deleting some paragraphs, adding other paragraphs, and the integration of some paragraphs so that the total paragraphs (15).

\section{Stability of the tool:}

The stability of the tool was verified using Alpha Kronbach formula, and the results of Table (3) illustrate this.

Table (3): Results of the Alpha Kronbach equation to verify the stability of the study tool:

\begin{tabular}{|c|c|c|}
\hline Axis & $\begin{array}{c}\text { Number of } \\
\text { paragraphs }\end{array}$ & $\begin{array}{c}\text { Alpha } \\
\text { coefficient }\end{array}$ \\
\hline $\begin{array}{c}\text { The first axis - scientific } \\
\text { values }\end{array}$ & 5 & 0.83 \\
\hline $\begin{array}{c}\text { The second axis - } \\
\text { religious values }\end{array}$ & 5 & 0.91 \\
\hline $\begin{array}{c}\text { The third axis - National } \\
\text { Values }\end{array}$ & 5 & 0.95 \\
\hline Total Stability & 15 & 0.89 \\
\hline
\end{tabular}

It is clear from Table (3) that the questionnaire in all its axes has an appropriate stability to be used for the purposes of this study. The total stability coefficient (0.89) is applicable. 


\section{Statistical Processing Methods:}

The researcher collected the scores of each main axis, and percentages were worked for these results. In order to perform the statistical analysis, the researcher found the value of a square as any, and was revealed in a square table as the level of statistical significance for each paragraph.

\section{Analysis, discussion and interpretation of the results:}

This section deals with the analysis and interpretation of the final results of the application of the research tools and the extent of their agreement and differences with the previous studies.

The First question: which was: "What is the role of children's television programs in the development of values for the kindergarten child from the teachers' point of view in Port Sudan locality, southern unit?

To answer this question, the arithmetical averages, standard deviations and percentage of the role of children's television programs in the development of values for kindergarten children in Port Sudan were extracted from the teachers' point of view..

Table (4) presents the arithmetical averages and percentages of the responses of the sample members on the three main axes of the questionnaire and a descending order by percentage.

Table (4) Calculation averages, percentages, standard deviations and the estimated degree of responses of the sample members on the three main axes of the questionnaire

\begin{tabular}{|c|c|c|c|c|}
\hline Axles & Average & deviation & Percent & degree \\
\hline $\begin{array}{c}\text { The first axis is } \\
\text { scientific values }\end{array}$ & 3.38 & 0.63 & 69.4 & medium \\
\hline
\end{tabular}




\begin{tabular}{|c|c|c|c|c|}
\hline $\begin{array}{c}\text { The second axis is } \\
\text { religious values }\end{array}$ & 3.30 & 0.71 & 63.6 & medium \\
\hline $\begin{array}{c}\text { The third axis is } \\
\text { National Values }\end{array}$ & 3.08 & 1.57 & 61.3 & medium \\
\hline Total average & 3.25 & 0.97 & 64.73 & medium \\
\hline
\end{tabular}

It is clear from the results of Table (4) that the total arithmetic mean of the role of children's TV programs in the development of kindergarten child'svalues from the teachers' point of view in Port Sudan was( 3.25) and (64.73\%) For a kindergarten child in Port Sudan is medium. In terms of ranking of axes, the center of religious values ranked first with an average of (3.38) and (69.4\%), followed by scientific values in second place with an average of (3.30) and a percentage of( 63.6\%)National values with an average score of (3.08) percentage $(61.2 \%)$. This confirms that the degree of the role of children's television programs in the development of values for kindergarten children in Port Sudan is medium.

The researcher pointed out that the media (television programs) are complementary to the family and other socializing institutions.

The current study is consistent with the study of Mohammed Jassim, Saeed Miftah (2015), Al-Hawli (2004) and Tasnim Mukheimer (2015). And differ with the study of Orabi Mahmoud (2006).

The Second question: which was: "What is the role of children's television programs in the development of the religious values of kindergarten children from the teachers' point of view? 
To answer this question, the arithmetical averages, standard deviations and percentage of the role of children's television programs were extracted in the development of the kindergarten child's values in Port Sudan from the teachers' point of view.

Table (5) : Arithmetic averages, percentages, standard deviations, and estimated degree of responses of the sample members to the axis of scientific values:

\begin{tabular}{|c|c|c|c|c|}
\hline $\mathrm{N}$ & Phrase & Average & deviation & Application \\
\hline 1 & $\begin{array}{c}\text { The programs that my children } \\
\text { watch increase their yield to the } \\
\text { language Programs seen by } \\
\text { children increase their ability in } \\
\text { mathematics courses }\end{array}$ & 3.89 & 0.86 & Big \\
\hline 2 & $\begin{array}{c}\text { Programs seen by children increase } \\
\text { their ability in mathematics courses }\end{array}$ & 3.44 & 0.91 & medium \\
\hline 3 & $\begin{array}{c}\text { Programs that my children watch } \\
\text { develop their general culture }\end{array}$ & 3.88 & 0.91 & Big \\
\hline 4 & $\begin{array}{c}\text { The programs that my children see } \\
\text { link their past, present, and future }\end{array}$ & 1.33 & 0.90 & Few \\
\hline 5 & $\begin{array}{c}\text { Programs that my children see } \\
\text { increase their knowledge of public } \\
\text { science }\end{array}$ & 3.39 & .56 & medium \\
\hline & \begin{tabular}{c} 
Total average \\
\hline
\end{tabular}
\end{tabular}

Table (5) shows that the role of children's TV programs in developing the kindergartenchild's scientificvalues in Port Sudan from the teachers' point of view is in a medium degree. In the previous table, the highest value in the scientific values included in the children's programs shown on television is the development of children's general culture and increasing their ability in mathematic course, and the lowest value was the 
link between children's present ,past and future. This resultis consistent with the study of Mohammed Jassim, SaeedMiftah (2015) and the study of Tasnim Mukhaimar (2015) and differs with the study of Orabi Mahmoud (2006).

THE third question: "What is the role of children's television programs in the development of the religious values of kindergarten children from the teachers' point of view?

To answer this question, the arithmetical averages, standard deviations and percentage percentages of the role of children's television programs in the development of the kindergarten child's religious values in Port Sudan were extracted from the teachers' point of view.

Table (6): The mean, percentages, standard deviations and the estimated degree of responses of the sample members to the axis of religious values:

\begin{tabular}{|c|c|c|c|c|}
\hline $\mathrm{N}$ & Phrase & Average & deviation & Application \\
\hline 1 & $\begin{array}{c}\text { TV affects the faith of my } \\
\text { children }\end{array}$ & 3.79 & 0.65 & Big \\
\hline 2 & $\begin{array}{c}\text { My children learn to fast through } \\
\text { what they watch on TV }\end{array}$ & 3.27 & 0.74 & medium \\
\hline 4 & $\begin{array}{c}\text { My children learn to pray } \\
\text { through what they see on TV }\end{array}$ & 4.33 & 0.52 & Big \\
\hline 5 & $\begin{array}{c}\text { My children learn zakat through } \\
\text { what they see on television }\end{array}$ & 3.96 & 0.79 & Big \\
\hline $\begin{array}{c}\text { He learns the Koran and the } \\
\text { relatioship between the relatives } \\
\text { and visiting the patient through } \\
\text { what he sees on television }\end{array}$ & 3.96 & 0.79 & Big \\
\hline
\end{tabular}

It is clear from table (6) that the role of children's television programs in the development of the kindergarten child's religious values is very significant. From the above table, the 
highest value in the religious values included in the children's programs shown on television is learn to pray, learn Quran, visit relatives and patients while the lowest value was fasting. It is clear that there is a significant role for children's television programs in developing their religious values from theTeachers' point of view.

This result is consistent with the study of Mohammed Jassim, Saeed Miftah (2015), the study of Ziad Ben Ali Mahmud (2011) and the study of Tasnim Mukhaimer (2015), with the study of Orabi Mahmoud (2006).

The fourth question: which is: "What is the role of children's television programs in the development of the national values of kindergarten children from the teachers' point of view?

To answer this question, the arithmetical averages, standard deviations and percentage of the role of children's television programs in the development of the national values of kinder garten child in Port Sudan were extracted from the teachers' point of view.

Table (7) presents the arithmetical averages and percentages of responses of the sample members on the axis of national values.

Table (7) Calculation averages, percentages, standard deviations and the estimated degree of responses of sample members to the axis of national values:

\begin{tabular}{|c|c|c|c|c|}
\hline $\mathrm{N}$ & Phrase & Average & deviation & Application \\
\hline 1 & $\begin{array}{c}\text { TV programs increase their } \\
\text { family membership }\end{array}$ & 1.62 & 0.86 & Few \\
\hline 2 & $\begin{array}{c}\text { TV programs increase their } \\
\text { affiliation to their country }\end{array}$ & 2.71 & 0.71 & medium \\
\hline 3 & $\begin{array}{c}\text { TV shows increase their state } \\
\text { affiliation }\end{array}$ & 1.18 & 0.42 & Few \\
\hline
\end{tabular}


Doi: 10.12816/jacc.2020.123862

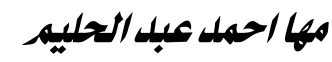

\begin{tabular}{|c|c|c|c|c|}
\hline 4 & $\begin{array}{c}\text { TV programs increase their } \\
\text { belonging to their neighbors }\end{array}$ & 1.15 & 0.59 & Few \\
\hline 5 & $\begin{array}{c}\text { TV shows increase their } \\
\text { belonging to their friends }\end{array}$ & 2.092 & 0.92 & medium \\
\hline & \begin{tabular}{c} 
Total average \\
\hline
\end{tabular} & $\mathbf{2 . 8 7}$ & $\mathbf{0 . 6 1}$ & Few \\
\hline
\end{tabular}

Table( 7) shows that the role of children's television programs in the development of the national values of the kindergarten child in Port Sudan was very low from the teachers' point of view and their mean score was 2.87 with a standard deviation of 0.61 . This indicates that the children's televisionprograms is with lownational values for the child.

This result is consistent with the study of Mohammed Jassim, Saeed Miftah (2015) and the study of Tasnim Mukhaimar (2015), while it differs with the study of Orabi Mahmoud (2006) and the study of Ziad Ben Ali Mahmud (2011).

\section{The main results of the study:}

The study has reached the following results:

1. Children's television programs has a role of a medium degree in the development of kindergarten child'svalues from the teachers' the point of view in Port Sudan locality.

2. Children's television programs has a role of a medium degree $r$ in developing the scientific values of kindergarten children in Port Sudan from the teachers' point of view.

3. Children's television programs has a significant role in the development of the religious values of kindergarten children from the teachers' point of view.

4. There is a small role for children's television programs in developing the national values of kindergarten children in Port Sudan from the teachers' point of view. 


\section{The main Recommendations:}

According to the results of the study the researcher recommend the following:

1. Focusing on the selection of children's programs that reflect the positive character, which indicates cooperation and tolerance among children and good behaviors.

2. Children's programs should include the greatest proportion of safety, reducing fear and alarm, and children's programs should be meaningful.

3 . Benefiting from the research of universities and research centers for children.

4. Television programs for children must be made according to our social culture, norms and tradition . 


\section{Reference:}

1-A friend, Amira Mohammed Yassin (1993), Islamic vision of the role of some educational institutions in the prevention of drug danger, unpublished MA, Umm Al-Qura University, Faculty of Education, Makkah, Saudi Arabia.

2-Abu Al-Enein, Ali Khalil Mustafa (1988). Islamic Values and Education, I, Ibrahim Ali Library, Medina, Saudi Arabia. 3-Edward Stashev and Rudy Pritz (D, T) TV programs, production and output, translated by: Ahmed Taher, I 3, Record Arab Foundation, Cairo, Egypt.

4-Al-Nashif, Abdul-Malik (1981) "Values and Methods of Teaching and Learning" EP / 13: Department of Education, UNRWA, Jordan.

5-Andre Glicksman (2000) The world of television between beauty and violence, translated by Wajih Semaan Abdel Masih, Publications of the National Project for Translation, Supreme Council of Culture, Cairo, Egypt.

6-Hijoo, Ghazi (1986) "Values, Attitudes and Methods of Teaching in Arabic Language (A36 / 86) Department of Education, UNRWA, MA, Al Quds Open University, Jerusalem, Palestine.

7-Mohammed Ahmed Sawalha (2003) An analytical study of the reality of values in a sample of children's stories, Journal of the Union of Arab Universities. Education and Psychology, Damascus, Vol 1, p

8-Tahtawi, Sayed Ahmed (1996) Educational Values in Quranic Stories, I 1, Arab Thought, Cairo, Egypt.

9-Tasneem Ahmed Mukhaimar (2015) Values in Children's Television Programs "Mbc3 Channel Programs", Master, Middle East University, Amman, Jordan. 
10-Wahida Bafdah Bidi (20017) Values in the channel program (mbc3) for children, published scientific paper, Journal of Standard, No. (42). 